\title{
Fostering Nursing Students' Informatics Competencies via A Web-based Information Literacy Course
}

\author{
Weichieh Wayne $\mathrm{Yu}^{\mathrm{u}^{*}}$, Ching-Yu Cheng ${ }^{1}$, Chunfu Charlie $\operatorname{Lin}^{2} \&$ Jenny Wang ${ }^{2}$ \\ ${ }^{1}$ Department of Nursing, Chronic Diseases \& Health Promotion Research Center, Chang Gung University of Science \\ \& Technology, Taiwan \\ ${ }^{2}$ Department of Applied Foreign Languages, National Formosa University, Yuling County, Taiwan \\ *Correspondence: Weichieh Wayne Yu, Dept. of Nursing, Chang Gung University of Science \& Technology, Chiayi, \\ Taiwan. Tel: 886-5-362-8800. E-mail: jamiemeetsworld@gmail.com
}

Received: June 3, 2013

doi:10.5430/jct.v2n2p11
Accepted: June 26, $2013 \quad$ Online Published: July 11, 2013

URL: http://dx.doi.org/10.5430/jct.v2n2p11

\begin{abstract}
This paper reports the development and implementation of a web-based nursing information literacy course aiming to promote informatics competencies of intended nurses. This particular 18-month course in school years 2011-2012 underwent three distinct phases: initial design, pilot-test and modification, and final implementation. Participants were senior students in a professional nursing college in Southern Taiwan. The researchers conducted the class in a predominately online setting, where all class work took place except for prearranged meetings for class issues and/or problems that occurred unexpectedly. The results showed that the majority of students perceived positively about the teaching method, felt that they gained more knowledge and skills about information literacy and had the abilities to apply these skills in their future nursing practices. This teaching model can serve as a reference for educators and administrators when considering to implement informatics curriculum for nursing students to create opportunities for competency before graduation.
\end{abstract}

Keywords: nursing Informatics; information literacy; web-facilitated learning

\section{Introduction}

Because of the rapid changes on computer and internet technologies and proliferation of information resources, information competency or information literacy becomes increasingly important. According to the Association of College and Research Libraries (2000), information literacy is defined as "a set of abilities requiring individuals to recognize when information is needed and have the ability to locate, evaluate, and use effectively the needed information." Different from computer skills that are merely computer use (ACRL, 2000; Bryson, 1991), information literacy involves understanding, accessing, evaluating, incorporating information into knowledge base, and using information effectively and correctly (ACRL, 2000). It contributes to self-directed lifelong learning and is considered as outcome abilities of college students. In health profession, study results showed that nurses' competency in retrieving and using internet information could support patients and families to use internet as a medium to obtain information since the Internet became an accessible information source (Gilmour, Scott \& Huntington, 2008). However, a literature review article pointed out that information literacy was a relatively new concept in health profession including nursing and there was especially a lack of publications about information literacy from Asian countries (Saranto \& Hovenga, 2004).

More health related academic and clinical institutions emphasize evidence-based practice to provide patients with safe and proper care. However, researchers pointed out that lack of time, lack of information accessibility and technology skills, and inadequate information search and appraisal skills were barriers for nurses to obtain proper information and perform evidence-based practice. The lack of information literacy skills lead nurses to use information that was accessible and convenient to them rather than to use information with quality (Bertulis, 2006). What worsened the situation were the publication biases namely selection bias, confounders, observation bias, and allocation concealment, in medical publications (Cohen, 2006). Information available to the public could be biased 
and nurses then could apply improper information to patients.

Current undergraduate nursing students mainly belong to Millennial generation, who were born between 1982 and 2002 (Strauss \& Howe, 2000). These Millennial students grew up with computers and in the Internet world. They respond to text messages and blogging, use online social networking tools such as facebook more often than traditional communication pathways (DeBoor \& Halpem, 2011; Lenhart, Madden \& Hitlin, 2005; Lenhart, Purcell, Smith \& Zickhur, 2010), obtain information or discuss school work on web. Traditional lectures are no longer appreciated ways of teaching and learning. In other words, web-based learning could be a better way to teach. Although most university students perceived themselves having good research skills, they could not perform accurate information searches or judge trustworthiness of health-related websites. They were also unclear about the concept of plagiarizing and citing references (Ivanitskaya, Boyle \& Casey, 2006). Therefore, there is a need to teach concept of information literacy and how information literacy is applied in health professions.

The purpose of this study was to develop a web-based course that fostered nursing students' competency in information literacy. At the completion of the course, students were expected to apply information literacy skills in nursing practice. This study was a three-semester (one and a half years) study. A web-based information literacy course was developed in the first semester. In the second term, seminars in which students participated, were held to evaluate the progression of the course. The term was summed up by students' project presentations. Students provided comments and suggestions regarding the course by completing a questionnaire. The course was then modified based on the comments and suggestions received from the seminar(s). The last semester was a final implementation of the revised course design.

\section{Theoretical Background}

Sweeney, Saarmann, Flagg and Seidman (2008) stated that many healthcare professionals admittedly lack technology and information skills often times as simple as their familiarity with computers. In light of the core competencies that health professionals shall possess, as set forth by Institution of Medicine (IOM), a number of researchers asserted that informatics competencies should be integrated into health curricula within the context to promote quality patient-centered care while enabling evidence-based practice (Bakken, Cimino \& Hripcsak, 2004; Desjardins, Cook, Jenkins \& Bakken, 2005). As computer technology evolves at an incredibly rapid pace, it is important to recognize the role not only of computer technology in education, but of the information technology in the nursing curriculum. For these healthcare experts to be able to mainstream with our fast-moving technology centered healthcare arena, fundamental skills must be taught, mastered and kept current. Although much efforts have been made on a fairly global level to incorporate information technology into nursing practice by defining nursing data sets and classification systems (Carty \& Rosenfeld, 1998), little is known and done about schools implement computer as well as information technology in the curriculum. Researchers, together with healthcare professionals and educators have made recommendations for teaching nursing informatics (Gonce-Winder, Kidd \& Lenz, 1993; McGonigle \& Eggers, 1991; Strength \& Keen-Payne, 1991), which included integrating nursing informatics into the nursing curriculum. More recent research has outlined the scope of computer literacy objectives (Nagle, 2007) and identified the technology learning needs of practicing nurses (Sweeney, Saarmann, Flagg \& Seidman, 2008).

Often seen as the early adopters of educational innovations, nursing educators have been pioneers in making use of a variety of educational technologies to facilitate learning. Use of simulations, for example has increased dramatically over the past decade in instruction/learning pedagogy. Successful application of simulation involves curricular consideration, development, detailed preparation as well as collaboration between faculty, staff and administration. Nonetheless, not all educators feel "ready" nor "confident" as this new technology is moving into the curriculum (Skiba, Connors \& Jeffries, 2008). There is also a thriving group of nurse educators who create active learning environment to engage students by incorporating E-learning, web-supported technologies, such as Blackboards, blogs, podcasts, screencasts, or more interactive/participatory Web 2.0 tools like clickers, and ever-so-popular social networking platforms in nursing curricula. Such transformation has aimed to shape the way nursing education is delivered and create opportunities for our next generation nurses. According to a study by Carnegie Foundation (2006), these nurses expect to:

1) de pervasive

2) involve a need for public performance

3) have a sense of interdependence

4) mirror practices of uncertainty 
5) not to be emotionless

6) have a sense of character and value

7) have a sends of personal responsibility

Nursing education has been forefront in some educational arenas, but still faced with many challenges. Skiba (2008) proclaimed that schools of nursing would experience a new type of digital divide as they strive to best prepare perspective nurses to practice in a transformed health environment. Such divide can be resulted due to the slow response of faculty to the integration of the emerging technological tools in curriculum. Furthermore, she noted there has been relatively little incorporation into the existing nursing curriculum of "knowledge, skills, and attitudes related to the use of informatics tools to facilitate communication among the interdisciplinary team and with patients, manage knowledge, diminish error, and support clinical decision-making (p.228)". Information literacy focuses on content, communication, analysis, information searching, and evaluation (NRC, 1999). To gain these abilities, the concept and skills of information literacy should be woven into the curriculum's content, structure, and sequence (ACRL, 2000). The dimensions of information literacy that include tool/emerging technology literacy, resource literacy, social-structural literacy, research literacy, publishing literacy, and critical literacy (Shapiro \& Hughes, 1996) were used to structure the course. The objectives of the course were set based on the standards for information literacy competency for higher education proposed by the Association of College and Research Libraries. The standards include determining the nature and extent of the information needed, accessing needed information effectively and efficiently, critically evaluating information and its sources, incorporating information into knowledge base, using information effectively, accessing and using information ethically and legally (ACRL, 2000).

\section{The Study}

This study aimed to demonstrate nursing faculty's efforts in the development of a web-based course to promote nursing students' information literacy competency. The study was a three-semester study that included a development of the course, pilot-test and modification, and final implementation of the revised course design. All class activities were done online except for predetermined periodical meetings for problem discussions.

\subsection{Nursing Informatics Definitions}

The American Nurses Association (2001) provided a description of informatics competencies for nurses ranging from "beginning" to "specialist". Beginning nursing informatics competency includes information management and computer literacy skills, for instance, using a word processor, presentation, database, or spreadsheet program. Experienced nursing informatics competency includes proficiency in information management and communication directly related to an individual's major area of practice. Informatics competency for the Specialist focuses on standards of practice as well as professional performance. This reported course was more geared to the developing competency of a beginning nurse at a generalist level.

\subsection{Course Design/Teaching Context}

The structure and topics of this web-facilitated course was based on dimensions of nursing information literacy and is shown in Figure 1. An 18-week class schedule was shown in the Appendix 1. Students in the course were evaluated based upon the following criteria:

$\diamond \quad$ Weekly journals

$\diamond \quad$ Literature search

$\diamond$ Website critique

$\diamond \quad$ Participation in discussion forums

$\diamond \quad$ Final project focusing on health-related issues.

The majority of the classes were taught/discussed online and students and the instructors met periodically only for clarification or discussion of unforeseen problems. All other class activities were completed online. E-campus (course management software) was the primary platform for online instruction for this course. It comprised sections of class information, bulletin board, class units/notes, assignment, discussion board, quiz, and evaluative questionnaires. Illustrations of each section were provided in Appendix 2.

\subsection{Participants}

The researchers recruited only nursing students in their final year in the study because they possessed sufficient 
knowledge with regard to health and nursing care. In addition, since the course was taught fully in English language, enrolling students needed to pass an intermediate-level proficiency test. Initially, eighty students expressed strong interest in taking part in this course. In the end, forty-two students who obtained the prerequisite and participated in the study, resulting in a rate of $53 \%$.

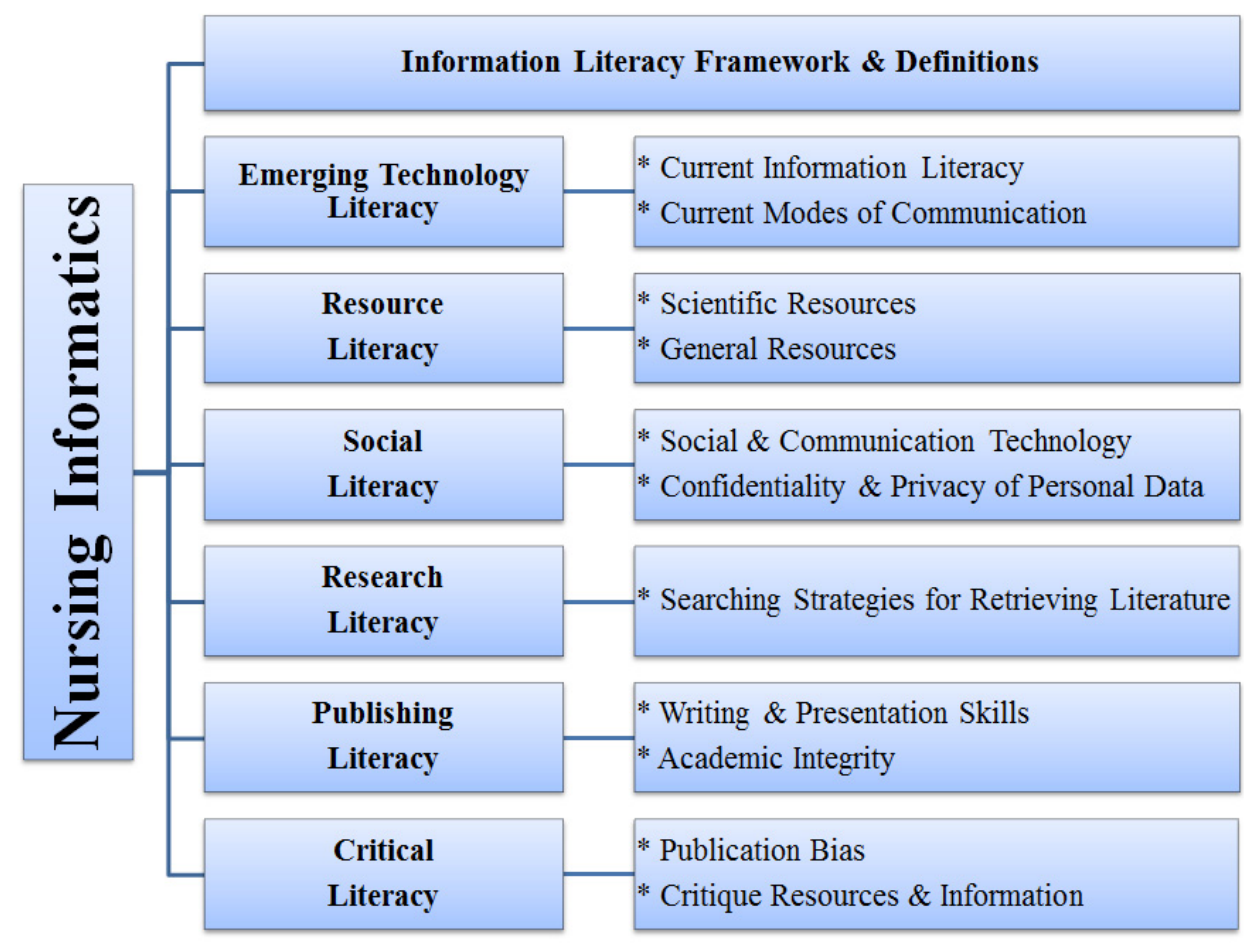

Figure 1: Structure of the Course

\subsection{Instrumentation for Course Evaluation}

A 15-item self-report online survey was used to collect data for this study to identify participants' perceptions of web-mediated teaching strategy (8 questions) and information literacy (7 questions). The instrument was developed by the researchers based on information obtained from the review of literature in the area of teaching/learning in the online/classroom settings (Kern, 2006; Kenny, 2000; Kimball, 1998; Mazdayasna \& Tahririan, 2008). The questionnaire was made available monolinqually in students' native language, Mandarin Chinese in order to avoid receiving any false response due to misinterpretations of the item(s). A five-point Likert scale was used to allow the participants to express their perceptions in the areas under investigation, with number " 1 " being Strongly Disagree (SD), number "2" being Disagree (D), number " 3 " being Undecided (U), number "4" being Agree (A), and number "5" being Strongly Agree (SA). Students were asked to rate their level of satisfaction about computer-mediated teaching/learning strategies and learning outcomes at the completion of the course.

\subsection{Validity and Reliability of the Instrument}

In order to establish the content (face) validity of the instrument, which was stated by Gay, Mills, \& Airasian (2006) as the instrument measuring what it is intended or what it claims to measure, the researchers presented it to a panel of three experts in the field of computer mediated instruction/learning, teaching pedagogy, and statistical analysis, who were asked to validate the content of the survey instrument by ensuring the overall inclusiveness of all the variables under investigation. The experts were also asked to review the survey for things such as unclear instructions, confusing, ambiguous or repetitive items, and overly complex or difficult sentence structure. The researchers then revised the instrument based on the constructive feedback received from the reviewers.

To establish the reliability of the survey instrument used, the researchers employed a test/retest method using 25 students, who were not the subjects for this reported study. The identical survey was completed by the participants twice. There was a waiting window of one week between the first and second administration of the instrument. There was a strong association between the two tests with a correlation coefficient of .78. In addition to the test/retest method, the researchers also performed Cronbach's Alpha reliability test. Cronbach's Alpha value was $.85, \mathrm{p} . \leq .05$. 


\subsection{Data Collection and Analytical Procedures}

At the end of the semester, a survey was administered to the students who were enrolled in this Nursing information Literacy class. Voluntary participation was ensured both through explicit verbal and written explanations. The participants could withdraw from the study at any time and that their participation would in no way influence their academic standing in the class where the questionnaires were distributed. Participants were informed verbally and in writing that they could decline to answer any items on the questionnaire. All students gave their consent and returned the questionnaire, resulting in a response rate of $100 \%$. The data collected were analyzed and presented descriptively.

\section{Findings}

As shown in Table 1, the majority of students perceived positively about computer-mediated learning that was used in the course and believed they could apply information literacy skills in nursing after completing the course. The students neither "Strongly Disagreed" nor "Disagreed" with the statements in the questionnaire; thus, these two categories were not presented in the Table.

Table 1: Perceptions of Computer-Facilitated Learning and Learning Outcomes

\begin{tabular}{|c|c|c|c|}
\hline & $\begin{array}{c}\text { Strongly Agree } \\
(\%)\end{array}$ & $\begin{array}{l}\text { Agree } \\
(\%)\end{array}$ & $\begin{array}{l}\text { Undecided } \\
\quad(\%)\end{array}$ \\
\hline \multicolumn{4}{|l|}{ Web-facilitated learning } \\
\hline 1. allows knowledge building. & 58.8 & 41.2 & 0.0 \\
\hline 2. promotes in-depth and advanced learning. & 58.8 & 41.2 & 0.0 \\
\hline 3. allows building computer skills. & 64.7 & 35.3 & 0.0 \\
\hline $\begin{array}{l}\text { 4. ensures that students are engaged and motivated in } \\
\text { learning }\end{array}$ & 35.3 & 47.1 & 17.6 \\
\hline 5. encourages collaborative (group) learning & 29.4 & 52.9 & 17.7 \\
\hline $\begin{array}{l}\text { 6. enables effective communication with the teacher } \\
\text { and peers. }\end{array}$ & 23.5 & 76.5 & 0.0 \\
\hline 7. helps lifelong learning. & 76.5 & 23.5 & 0.0 \\
\hline 8. promotes self-learning. & 58.8 & 35.3 & 5.9 \\
\hline \multicolumn{4}{|l|}{ After completing the course, $I$} \\
\hline $\begin{array}{l}\text { 9. am more familiar with and capable of using various } \\
\text { technological (Web 2.0) tools. }\end{array}$ & 64.7 & 35.3 & 0.0 \\
\hline $\begin{array}{l}\text { 10. understand more about information literacy and its } \\
\text { framework. }\end{array}$ & 35.3 & 58.8 & 5.9 \\
\hline $\begin{array}{l}\text { 11. Can explain clearly terms related to information } \\
\text { literacy. }\end{array}$ & 41.2 & 52.9 & 5.9 \\
\hline $\begin{array}{l}\text { 12. know how to apply information literacy skills in } \\
\text { nursing practices. }\end{array}$ & 47.1 & 52.9 & 0.0 \\
\hline $\begin{array}{l}\text { 13. can effectively use e-books, e-journals, world wide } \\
\text { web, and library resources. }\end{array}$ & 58.8 & 41.2 & 0.0 \\
\hline $\begin{array}{l}\text { 14. can organize and manage information much more } \\
\text { effectively. }\end{array}$ & 52.9 & 47.1 & 0.0 \\
\hline $\begin{array}{l}\text { 15. can use various information technology tools to } \\
\text { present nursing information. }\end{array}$ & 41.2 & 58.8 & 0.0 \\
\hline
\end{tabular}

\section{Discussion \& Conclusion}

Research aimed to evaluate the impact of nurses' attitudes towards the outcome of computer facilitated teaching/learning (Burkes, 1991; Scarpa, Smeltzer \& Jasion, 1992; Thomas, 1990) have voiced concerns over courses that were designed to encompass major areas of computer use in nursing. Nursing students must be prepared to manage information and to research and communicate through nursing informatics courses. The findings of this study revealed that effective communication and knowledge building were positively perceived by the participants through the web-facilitated nursing information literacy course. Students also responded that they became more knowledgeable in terms of nursing information literacy and its framework, and were capable of using various technological tools to communicate, organize, research and present information associated with nursing practices. 
The results of this study also add to the literature by supporting Grobe (1988) and Bryson's (1991) claim, indicating that nurses need to accept the computer as a tool of their profession; furthermore, information-literate nurses have to have a basic knowledge about computers so that they are able to use technology-facilitated instruction tools/programs in practice of nursing.

The influx of technology, access and rate of exchange within the organization requires health professionals to be skillful at management of information in a digital environment. This purpose of this web facilitated information literacy course was five-fold and included the following: (1) to provide a sound basis of the information literacy framework; to develop proficient and sensible knowledge in (2) tool literacy; (3) resource literacy; (4) research literacy and (5) communication literacy. Ultimately, this course will serve as a reference for educators and administrators when considering to implement informatics curriculum for nursing students to create opportunities for competency before graduation and enhance the drive for lifelong learning.

Overall, students rated positively toward the content delivery and learning outcome of this web-facilitated information literacy course. The impact of students' computer skills and their ability to use the required media needs additional examination. It is also suggested that the need for prerequisite skills and competence in using the course management software (eg. E-campus) prior to taking an online class should be studied. The technical aspects of a truly integrated online learning experience relies on students' ability to navigate their way through the course management system, to use the media available to them, and to collaborate via an multimedia learning environment. How much these basic technical skills contribute to students' impressions of the online experience and their actual performance in the class is unknown and should be studied.

\subsection{Limitations of the Study}

The findings of this study should not be generalized to other populations. Although anonymity of the participants was assured, the findings are limited to the honesty of the participants in completing the instrument. It is possible that students might have responded in a way that presents them as more knowledgeable, competent, and hard working. Although the researchers strived to present a neutral view of collaborative online learning, it is possible that questions were presented in such a way that developed bias based on their desire to present an effective online program.

The researcher's data is limited to the online postings and responses that the students submitted. There were no personal discussions or dialogue to draw additional data from. The lack of qualitative data is a limitation of the study.

\subsection{Implications for Further Research}

Variables that impact students' perceptions of effective online collaborative learning merit additional research. Models including variable not examined in this study should be considered, as well as additional research on the impact of the use of various media, participation in (online) discussion, and generating interest in the class topics.

\section{Acknowledgements}

This project and publication were funded in part by the National Science Council of the Republic of China (Taiwan) (NSC\# 101-2511-S-255-005-). Any opinions, findings, conclusions or recommendations expressed in this publication are those of the authors and do not necessarily reflect the views of the National Science Council. Data collection and analyses were performed by the authors of this report. The authors of this report include researchers and/or educators affiliated with private and public universities in Taiwan. Wei-Chieh Wayne Yu of the Chang Gung University of Science \& Technology, is the lead and corresponding author of this report. You may contact him at 886-988972687, or via e-mail at jamiemeetsworld@gmail.com or by mail at No.2, West Sec. Chia-Pu Rd. Pu-tz City, Chiayi County 613, Taiwan (R.O.C.).

\section{References}

Association of College \& Research Libraries (ACRL). (2000). Information literacy competency standards for higher education. Chicago: Association of College \& Research Libraries.

Bakken, S., Cimino, J. J., \& Hripcsak, G. (2004). Promoting patient safety and enabling evidence-based practice through informatics. Medical Care, 42(2), 49-56. http://dx.doi.org/10.1097/01.mlr.0000109125.00113.f4

Bertulis, R. (2008). Barriers to accessing evidence-based information. Nursing Standard, 22(36), 35-39.

Bryson, D. B. (1991). The computer literate nurse. Computers in Nursing, 9(3), 100-107. 
Carty, B., \& Rosenfeld, P. (1998). From computer technology to information technology: Findings from a national study of nursing education. Computers in Nursing, 16(5), 259-265.

Cohen, J. (2006). A new 'publication bias': the mode of publication. Reproductive Biomedicine Online, 13(5), 754-755. http://dx.doi.org/10.1016/S1472-6483(10)60666-9

DeBoor, T., \& Halpem, L. K. (2010). Creating \& connecting: Research and guidelines on online social and educational networking. Retrieved from http://www.nsba.org/site/view.asp?CID=63\&DID=41340

Desjardins, K. S., Cook, S. S., Jenkins, M., \& Bakken, S. (2005). Effect of an informatics for evidence-based practice curriculum on nursing informatics competencies. International Journal of Medical Informatics, 74, 1012-1020. http://dx.doi.org/10.1016/j.ijmedinf.2005.07.001

Gilmour, J. A., Scott, S. D., \& Huntington, N. (2008). Nurses and internet health information: a questionnaire survey. Journal of Advanced Nursing, 61(1), 19-28.

Gonce-Winder, C., Kidd, R. O., \& Lenz, E. R. (1993). Optimizing computer-based systems use in health professionals' education programs. Computers in Nursing, 11(4), 197-202.

Ivanitskaya, L., I., Boyle, O'., \& Casey, A. M. (2006). Health information literacy and competencies of information age students: results from the interactive online research readiness self-assessment (RRSA). Journal of Medical Internet Research, 8(2), e6. http://dx.doi.org/10.2196/jmir.8.2.e6

Lenhart A., Purcell, K., Smith, A., \& Zickhur, K. (2010). Social media \& mobile Internet use among teens and young adults. Washington, DC: Pew Internet \& American Life Project. Retrieved from http://pewintemet.org/Reports/2010/Social?Media?and?Young?Adults.aspx

Lenhart, A., Madden, M., \& Hitlin, P. (2005). Teens and technology; Youth are leading the transition to a fully wired and mobile nation. Washington, DC: Pew Internet \& American Life Project.

McGonigle, D., \& Eggers, R. (1991). Establishing a nursing informatics program. Computers in Nursing, 9(5), 184-188.

Nagle, L. M. (2007). Everything I know about informatics, I didn't learn in nursing school. Canadian Journal of Nursing Leadership, 20(3), 22-25.

National Research Council. (1999). Commission on Physical Sciences, Mathematics, and Applications. Committee on Information Technology Literacy, Computer Science and Telecommunications Board. Being Fluent with Information Technology. Washington, D.C.: National Academy Press. Retrieved from http://www.nap.edu/books/030906399X/html/

Saranto, K., \& Hovenga, E. J. S. (2004). Information literacy-what it is about? literature review of the concept and the context. International Journal of Medical Informatics, 73, 503-513. http://dx.doi.org/10.1016/j.ijmedinf.2004.03.002

Shapiro, J. J., \& Hughes, S. K. (1996). Information literacy as a liberal art. Educom Review, 31(2), 31-36. http://net.educause.edu/apps/er/review/reviewarticles/31231.html

Shulman, L. (2006). Balanced education teachers students habits of mind, hand, heart. Retrieved from http://http://php.louisville.edu/news/news.php?news $=591$

Skiba, D. J., Connors, H. R., \& Jeffries, P. R. (2008). Information technologies and the transformation of nursing education. Nursing Outlook, 56, 225-230. http://dx.doi.org/10.1016/j.outlook.2008.06.012

Strauss, W., \& Howe, N. (2000). Miltennials rising: The next great generation. New York, NY: Vantage Press.

Strength, D. E., \& Keen-Payne, R. (1991). Computerized patient care documentation: Educational applications in the baccalaureate curriculum. Computers in Nursing, 9(1), 22-26.

Sweeney, N. M., Saarmann, L., Flagg, J., \& Seidman, R. (2008). The keys to successful online continuing education programs for nurses. The Journal of Continuing Education in Nursing, 39(1), 34-40. http://dx.doi.org/10.3928/00220124-20080101-09 


\section{Appendix 1- Class Schedule}

\begin{tabular}{|c|l|}
\hline Week & \multicolumn{1}{|c|}{ Topics } \\
\hline 1 & Introduction/ Nuts \& Bolts \\
\hline 2 & Definition and Framework of InformationLiteracy \\
\hline 3 & Scientific Resources for Health Related Information \\
\hline 4 & $\begin{array}{l}\text { Modes of Electroric CommuricationExisting Information } \\
\text { Technology for Data Management \& Transmission }\end{array}$ \\
\hline 5 & Effective Search Strategies for Retrieving Literature \\
\hline 6 & General Resources for Health RelatedInformation \\
\hline 7 & Critique of A Range of Resources \\
\hline 8 & Review \& Reflection \\
\hline 9 & Organization and Management of Resources \\
\hline 10 & Publicationbias \\
\hline 11 & Midterm Evaluation \\
\hline 12 & Project Day \\
\hline 13 & Academic Integrity \\
\hline 14 & Skills for Scholarly Writing \\
\hline 15 & $\begin{array}{l}\text { Safety and Privacy Related to Communication of Patient- } \\
\text { sensitive Data }\end{array}$ \\
\hline 16 & Skills for Effective Presentations \\
\hline 17 & Group Presentation(I) \\
\hline 18 & Group Presentation(II) \\
\hline & \\
\hline 10
\end{tabular}




\section{Appendix 2-Section Snapshots of The Course}

\section{Class information}

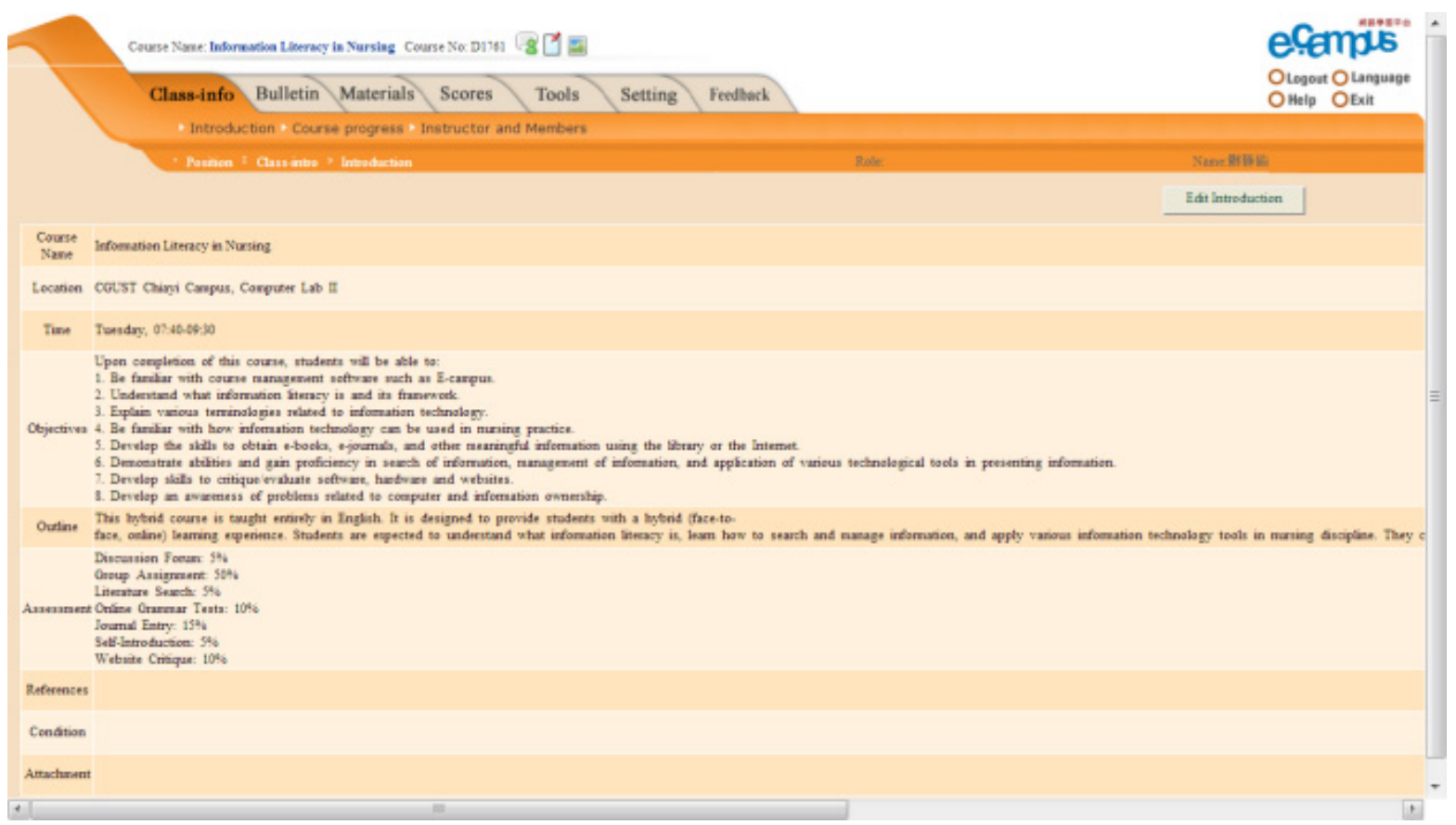

\section{Bulletin board \& announcements}

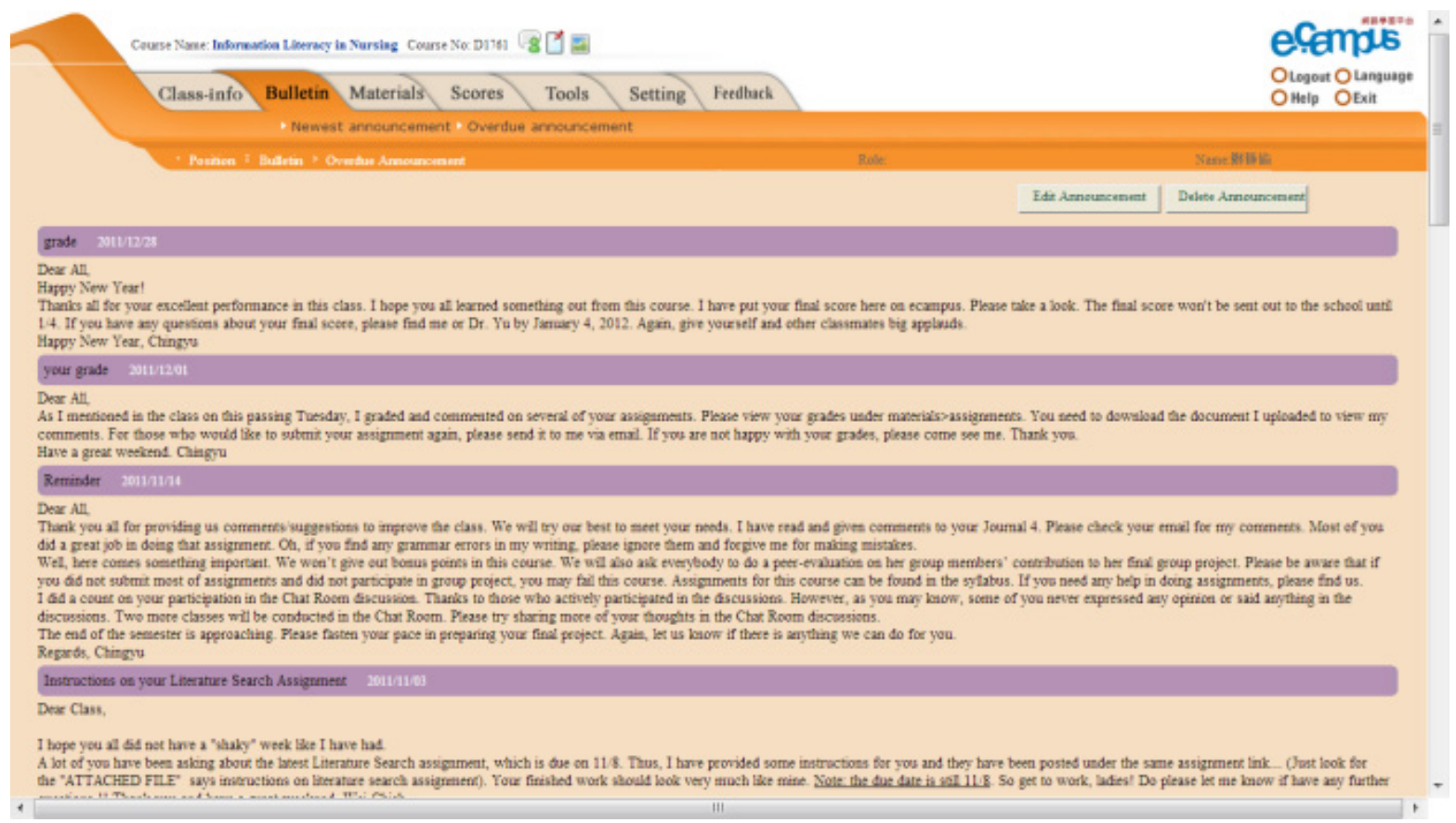




\section{Class materials}

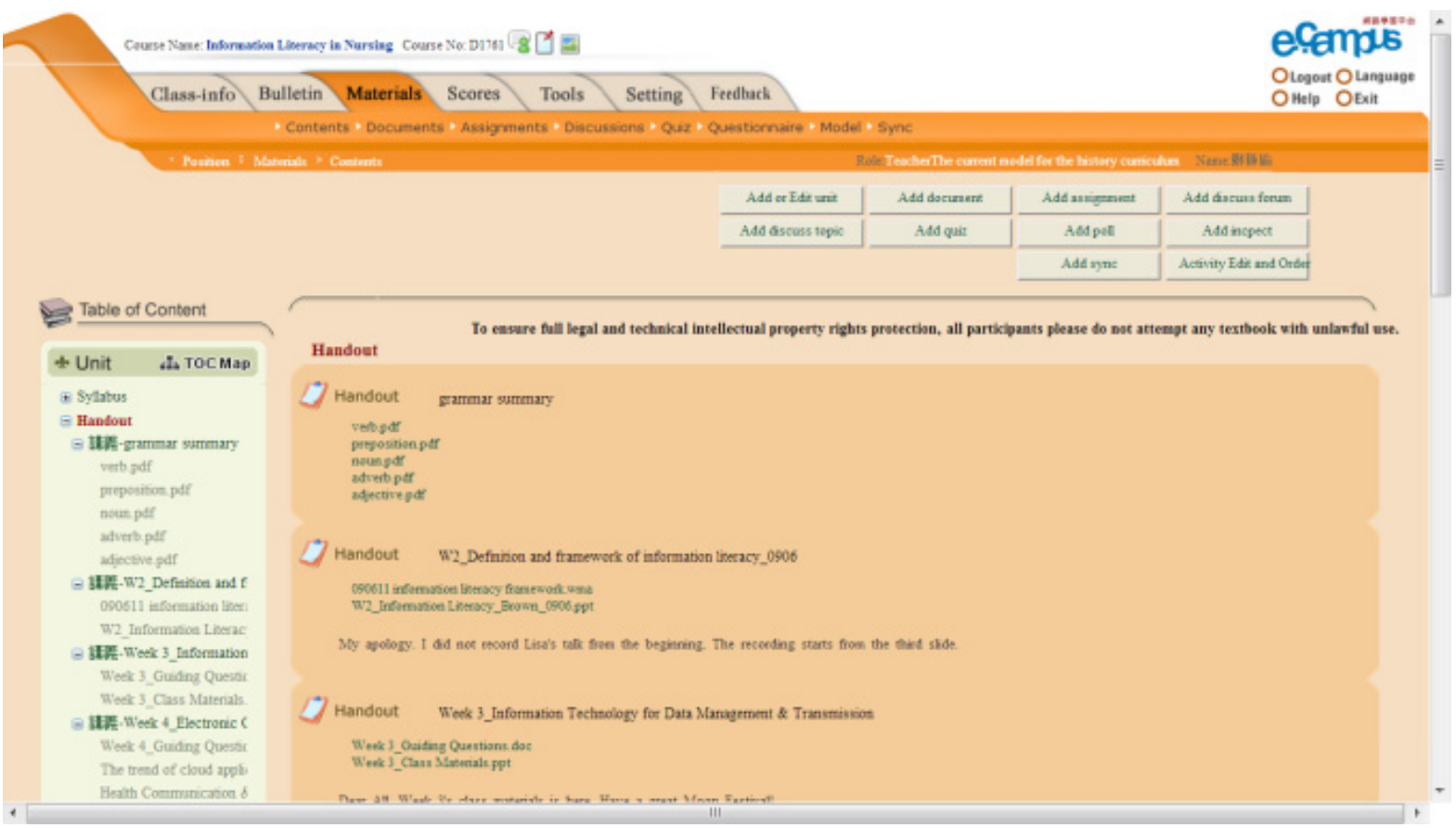

\section{Class assignments}

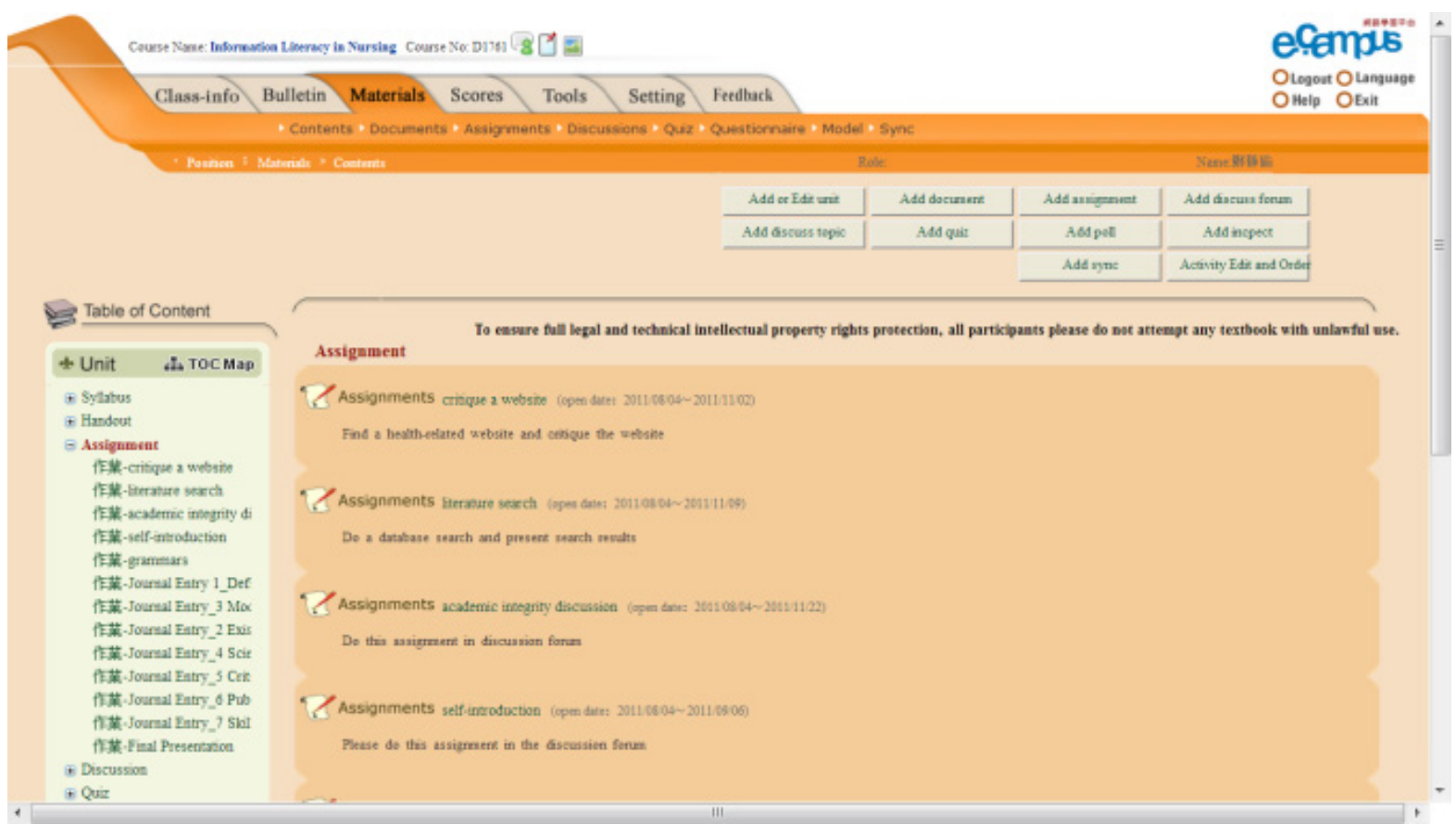




\section{Discussion board}

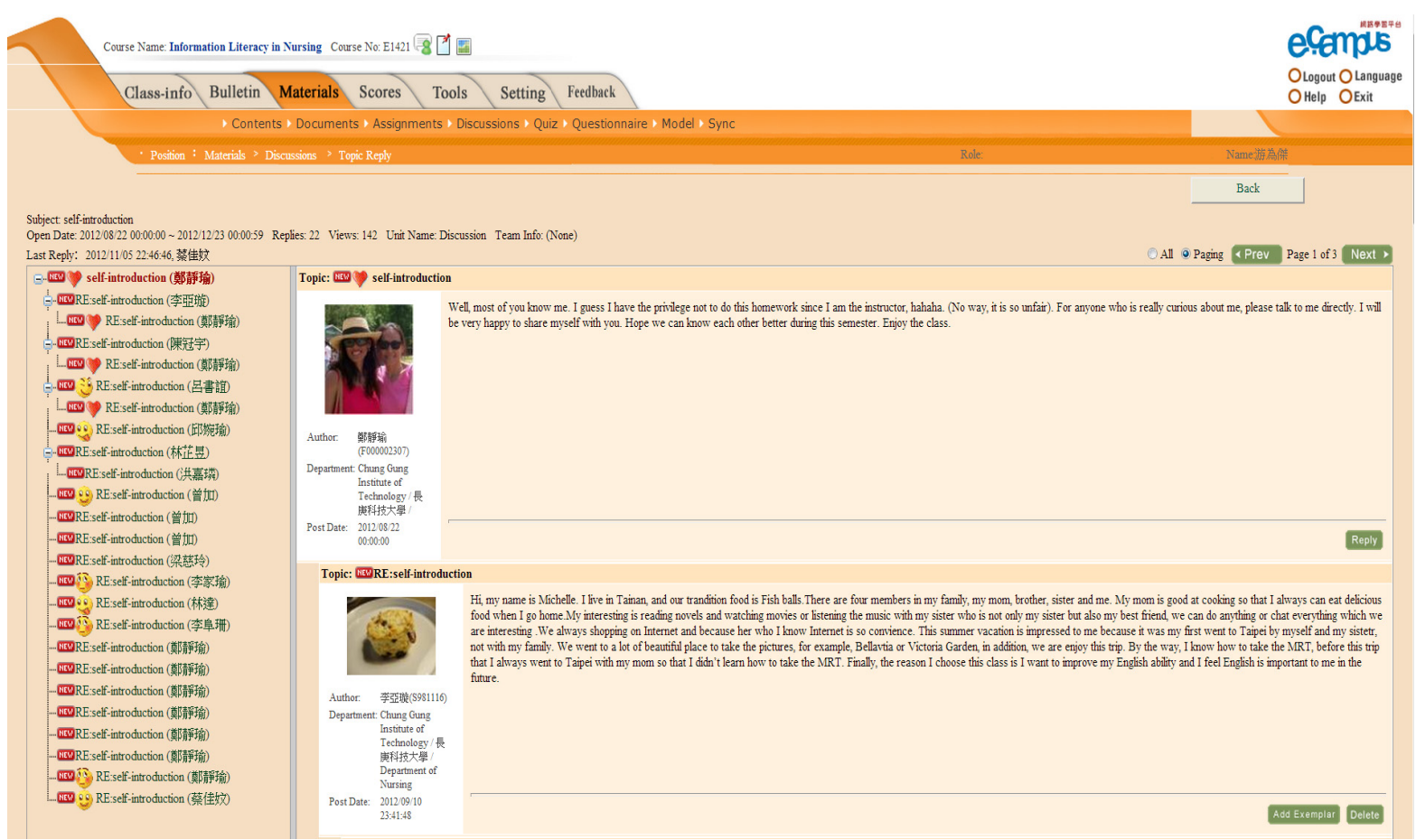

